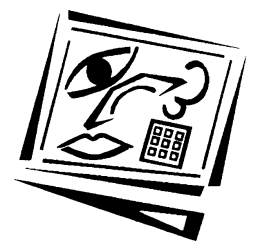

\title{
Reconnecting the classroom: E-learning pedagogy in US public high schools
}

\author{
David Huffaker \\ Georgetown University, USA
}

Giventhat most of the educational use of the Internet by American high school students occurs outside the school day, and outside the direction of teachers, this article reviews e-learning pedagogy and implementation in schools, with a view to enhancing learning both inside and outside the classroom. Key concepts such as active learning, metacognition and transfer of learning, may be promoted by e-learning applications that emphasise active engagement, social learning, continuous feedback and real world applications. This paper also explores some implementation issues including teacher training, content and application standardisation, cheating among students, and software filters and surveillance. Recommendations are made about informing and training educators as the first step in promoting classroom re-connection with outside school use of the Internet by students.

\section{Introduction}

Using the Internet has become a standard for today's youth. Internet access and usage have continued to grow - recent studies found that more than $78 \%$ of children between the ages of 12-17 go online (PEW, 2001:ii). Not surprisingly, completing schoolwork is one of the common practices for online teenagers.

The educational uses of the Internet are diverse and expansive, and children are using the Internet to enhance their educational experience in a variety of ways. The Internet offers opportunities to organise and multitask assignments and use state of the art research, as well as provide an arena for children to collaborate with online peers and share information. Children even communicate with virtual teachers and study groups, or pursue online classes. 
Unfortunately, students "report that there is a substantial disconnect between how they use the Internet for school and how they use the Internet during the school day and under teacher direction. For the most part, students' educational use of the Internet occurs outside of the school day, outside of the school building, outside the direction of their teachers" (PEW, 2001:iii).

The integration of Internet related assignments or multimedia into traditional curriculum leaves much to be desired. Most students are using the Internet outside of the direction of their teachers. They are beginning to navigate their own learning path, creating a curriculum derived from personal interests and self discovery, a path that signifies a possible communication gap between teachers and students. If teachers are the gatekeepers to fusing technology in the classroom, an evaluation of how that implementation might occur remains essential to educators, public policy makers, parents and students.

The interplay between Internet usage inside and outside the classroom raise concerns about the education system, and particularly, the role of the teacher in this process. To what extent does utilising the Internet, and in particular, e-learning, affect pedagogy in secondary education?

Given the divide between students and teachers in utilising the Internet, this paper hypothesises that e-learning, which utilises network technologies in order to create and facilitate learning, offers a variety of ways to enhance pedagogical approaches, especially in areas denoted by the USA's National Research Council. Active learning, metacognition and a transfer of learning are fostered through active engagement, social learning and continuous feedback, all reared from e-learning's distinct technical advantages. Furthermore, this paper considers the costs and externalities involved with e-learning, and makes recommendations for implementation.

In order to validate this hypothesis, this paper will proceed as follows. First, the paper will examine the key findings of the new "science of learning" as defined by the National Research Council. Second, it will identify ways in which e-learning embraces the new science of learning and how it enhances classroom design. Third, it will analyse the costs and externalities that affect policy choices by educators and school administrators. Finally, the thesis will identify possible strategies for implementing technology into curriculum, strategies that achieve the essential goals of the education system. 


\section{The new science of learning}

The US National Research Council, which was organised by the National Academy of Science in 1916 for the purposes of advancing knowledge and advising the federal government, completed a 2-year study on how people learn, and explored how to link the findings to actual classroom practice. One of the essential findings regards active learning, where students take control of their learning by recognising when they understand and when they need more information (Bransford, Brown, and Cocking, 2000:12). This ability to monitor their mastery of skills, make self assessments and reflect on understanding, often referred to as metacognition, demands new approaches to creating classroom environments.

The new science of learning also advocates improving transfer of learning, where students take previously acquired knowledge and apply it to new situations (Bransford et al, 2000:235).

The key concepts of the National Research Council studies include (Bransford et al, 2000: 14-18):

1. Students come to a classroom with preconceived notions about how the world works. The failure of a teacher to recognise these preconceptions results in a failure for students to grasp new concepts.

2. Students develop competencies by understanding facts and ideas, and organising knowledge in ways that can be easily retrieved and applied.

3. Students must embrace a metacognitive approach to learning, where they identify learning goals and monitor their progress in achieving those goals.

These findings have a direct impact on the way teachers might construct a learning environment. First, they have to draw out and work with the preconceptions of their students. Next, they have to provide a foundation for factual knowledge that includes real world examples. Finally, they have to incorporate metacognitive skills into their curriculum (Bransford et al, 2000:19-22), which not only engage, but also empower the students.

The new science of learning argues for classroom design that is learner centred. Teachers must pay close attention to the progress of each individual, help learners become aware of their own progress, and link classroom learning to other aspects of a student's life (Bransford et al, 2000:23-26). The science of learning also argues for classroom design that is community centred, fostering collaborative learning efforts that teach students the value of working together toward similar intellectual or 
project goals. This occurs when students ask each other questions, help each other to solve problems, and build on each other's knowledge (Bransford et al, 2000:25).

Building classroom environments should consider the goals of the teacher and the goals of the student. Teachers must focus more attention on the individual, while fostering cooperative and collaborative learning activities. This sounds like a challenge for teachers in culturally diverse, overpopulated classrooms. Yet as the student demographic and learning objectives change over time, so have the tools of technology (Bransford et al, 2000:246). There are many ways technology can aid teachers in the classroom.

E-learning applications, for instance, offer opportunities to actively engage the student, foster collaborative work, provide the student with continuous feedback, and aid in a transfer of learning. As a network technology, e-learning remains highly scalable - it can be transferred from 10 to 10,000 to 100,000 with little additional costs - and easily modularised, where information can be broken down in discrete units and reusable components (Horton, 2001:174). An analysis of the impact of e-learning demonstrates many areas for enhancing learning situations and embracing the concepts of the new science of learning.

\section{Impact of e-learning}

\section{Active engagement}

Children and adolescents spend an exorbitant amount of time with various forms of media outside of school (Calvert, 1999) and providing classroom instruction which mirrors the engaging production features of television or video games may capture the attention of students or motivate them to learn. Digital technologies involve a combination of media forms, from animated text, graphics and sound to full motion video. These technologies can take the form of presentations, simulations, or even games and provide teachers an extra tool to enhance their delivery of information.

Production techniques are only one aspect in engaging students to learn. Interactivity, which can be defined as empowering the user to control the environment (Phillips, 1997) truly engages the learner. By having to navigate their path through the system, the metacognitive approach to learning is incorporated. Students are aware of their learning path, and must actively engage the system to progress. 


\section{Social learning}

Many critics of e-learning envision an isolated learning environment, utilising rote memorisation or 'drill-n-practice' techniques. And certainly those models exist, but e-learning offers many applications for encouraging social activity; for instance a collaborative project such as The Globe Program, where children work in groups from different schools and contribute scientific measurements for different subjects, such as atmosphere or hydrology, to working scientists who measure and analyse all collected data (GLOBE, 2002). This allows students to work toward a common goal with a real world application. Even message boards, email correspondence and chat rooms offer students a chance to discuss ideas or project tasks... and to get their voice heard (Cassell, 2002).

Creating collaborative learning environments really embraces the concept of active learning - students actively "construct" their knowledge with peers and teachers, creating an arena where different discourse and learning styles can comfortably coexist (Roschelle, Pea, Hoadley, Gordin, Douglas \& Means, 2000:79). Because children and adolescents often construct identity or fulfill social needs based on their role in a group or community, constructing classroom environments that stimulate group learning can be a powerful motivator (Roschelle et al, 2000: 80).

\section{Continuous feedback}

According to the new science of learning, classroom design must be learner centred. Students need individual time with the educational content, as well as community time. There is a challenge in how teachers can provide equity in the classroom, especially when they must divide the number of students by the length of class time. If one student is far behind and requires extra help, other students get less attention. E-learning provides an excellent aid for teachers in providing continuous feedback to students. Multimedia applications, for instance, can provide practice examples and quizzes to provide immediate results on the student's abilities to grasp the concepts. Software programs such as Kaplan's SAT/PSAT Test Prep CD-Rom actually figures out a student's weakest knowledge areas, and customises the curriculum to improve those skills.

\section{Transfer of learning}

E-learning allows students to use knowledge they understand and apply it in different contexts. For instance, students can apply recently acquired understanding to problems they encounter in the real world. Students have access to the data professionals use: they can witness an 
archeological dig, for example, or view the latest images from the Hubble Space Telescope. Using the Internet to communicate with others, students have an opportunity to become partners with scientists, business people, or policy makers, empowering students to realise they can make an impact (Roschelle et al, 2000: 83).

The International Education and Resource Network (iEarn) is a global nonprofit organisation that encourages students to use the Internet to collaborate on educational projects (IEARN, 2002). Typically the forums are created and moderated by the students themselves, and each project involves learning fundamental concepts and then applying them to real world problems. Not only does a transfer of learning help children and adolescents realise they have an impact in the real world, but society gets to leverage additional knowledge and data from new sources.

\section{Technical advantages}

E-learning tools offer distinct technical advantages to aid in classroom learning: First, it's highly scalable. Once an application is developed, it can be deployed to an infinite number of users without incurring significant additions in time or cost (Horton, 2001:174). Applications can be designed to the "lowest common denominator" and become transferable locally or globally despite differences in network architecture or speed. The nature of scalability permits e-learning applications to remain flexible and adapt to new learning situations.

E-learning content can be broken down into discrete units of information. Modularisation, or packaging e-learning content into reusable modules which can be assembled for different learning needs, demonstrates another area of flexibility. For instance, modules of a Biology 101 course may be integrated into a Biology 202 course as refresher material. A mathematics class may need a summary module of physics concepts, or a literature course can add history modules to set the stage of a story. Modularisation demonstrates three important concepts:

1. Reusable components that can be integrated across disciplines.

2. Modules that are only written once, saving time and effort for future endeavors.

3. Content creation that force agreements and standards among educators. 
Scalability and modularisation promote a general cost effectiveness in designing courses. Reusable e-learning components reduce course resources even when student populations increase (Twigg, 2002:129). The possibility of reducing personnel costs also exists; e-learning can reduce the time it takes to write lesson plans or design course content. Teachers might have opportunities to spend more time motivating and coaching students, while schools may spend less money to design curriculum (Twigg, 2002:137).

Of course, it will become increasingly important to utilise standardised components in e-learning applications (Rosenberg, 2001:170). If e-learning developers can agree on a set of standards for software design, educators will be able to incorporate e-learning tools from different vendors in a seamless fashion. Educators will spend less time troubleshooting technical challenges and more time enhancing the learning experience. Software developers will be able to create third party plug-ins to enhance traditional course management platforms such as Blackboard's Course Management Software. (Blackboard, 2002), or add tools to improve multimedia production software such as Macromedia's Authorware (Macromedia, 2002).

\section{E-learning and the new science of learning}

The National Research Council found that classroom design should focus on active learning, metacognition and a transfer of learning. Second, the new science of learning encouraged classroom to be learner centred and community centred. E-learning reflects these concepts in a variety of ways:

1. E-learning applications can be personalised, provide feedback, and utilise navigation to individual users to guide their learning path.

2. E-learning applications involve communication tools that foster cooperation and collaboration between students despite temporal or spatial constraints.

3. E-learning applications can teach students fundamental concepts with real world treatments. Students can communicate with professional scientists or leaders, observe up to date scientific data and simulations, and participate in projects that expand a knowledge base.

4. E-learning applications offer unique technical advantages, suggesting new opportunities in how to design a course or learning experience. Reusable components that are scalable allow the ability to easily customise, modify and deploy educational content. 


\section{E-learning costs and externalities}

E-learning may incorporate the new science of learning, and Internet access may continue to grow inside and outside the classroom (NCES, 2001), but educators and policy makers have to consider other factors before implementing technology into the education system. These costs and externalities provide both challenge and opportunity, however, and an understanding of these issues is crucial before proceeding to actual deployment.

\section{Training teachers to use e-learning}

School administrators and policy makers may feel more costs and time are consumed by training teachers to use e-learning applications. There may be an initial resistance for some teachers to include new activities in their classroom design. It may take longer to train teachers who do not understand how to use computers and Internet technology in the classroom, and it may produce some inequities. Extra time and money will have to be leveraged to develop the necessary training tools. Once again, these initial costs result in a significant savings over time, and the possibility of running more efficient and higher quality learning environments.

There are also ways to speed up training time and reduce costs. By training a series of teachers who go and train other teachers in a pyramid can alleviate a lot of these issues. The Advocacy Project's (2002) eRiders, for instance, are local technical experts who are trained to use computers and/or software applications and are sent into their respective countries to train others. This has been a huge success for international development projects.

\section{Standardisation}

Development and training are not the only factors in choosing e-learning as a possible educational enhancement. Choosing appropriate vendors, making sure that e-learning integrates with previous hardware and network architecture, and maintaining flexible and scalable solutions that will have longevity are important concerns. Certain standards in elearning already exist: the language of the Internet such as HTML and programming standards such as ASP, PHP and Cold Fusion represent standards in development of tools. Standards organisations such as EDUCAUSE's Instructional Management Systems Projects (IMS, 2002), which set guidelines for e-learning development that many vendors already follow (Rosenberg, 2001:169), and the IEEE Learning Technology Standards Committee (IEEE, 2002), which certify and accredit contributions from other 
organisations, and publish official industry standards and guidelines (Rosenberg, 2001:169), promote the agreement and use of standards.

There are several reasons for standards being important in e-learning design and implementation:

1. Standardisation encourages interoperability between software and hardware components, making it easier to deploy e-learning applications into local, regional, statewide or even national school systems.

2. Standardisation encourages innovation as more vendors have opportunities to join the market with new products or enhancements to previous products.

3. Standardised products make it easier for training, as new products or versions are based on similar precepts and not proprietary systems.

\section{Academic integrity}

Even when e-learning applications are introduced into classroom settings, new concerns about how students will utilise the technology remains an issue for educators. The chief concern might be academic integrity and the ability for students to cheat. The Internet may make it easier for students to plagiarise from sources on the Web, and make it harder for teachers to trust the resources as reliable. The Center for Academic Integrity published a report that found cheating via the Internet to be widespread in high schools, and term paper mills and web sites make it easy for students to rationalise cheating (McCabe, 2001). Cheating remains an issue whether or not e-learning is implemented in a classroom, and it is important for educators and administrators to encourage responsibility in students and foster activities where plagiarism is not an easy option.

\section{Software filters and surveillance}

The Children's Internet Protection Act (CIPA), which attempts to protect children from viewing obscene or harmful material, went into effect in April 2001 (ALA, 2002). The primary method of protection was to restrict funding to schools and libraries that did not use filtering software on all computers with access to the Internet (FCC, 2002). The FCC defined material that was "harmful to minors" as any picture, image, graphic or other visual depiction that "appeals to prurient interest in nudity, sex or excretion," or depicts "an actual or simulated sexual act or sexual contact" (IFEA, 2002). Although CIPA is currently a case with the US Supreme Court regarding First Amendment violations (ALA, 2002), use of software filtering will be a significant issue for schools implementing e-learning. 
The current state of software filters may not be "smart" enough to protect minors from indecent material as expected. If a student is trying to find information on breast cancer or sexually transmitted diseases, for instance, the information may be blocked by the filters. On the other hand, granting students complete access to Internet pornography sites or obscene pictures may be problem - considered as both harmful and distracting.

There is also software for network administrators to view what pages Internet users access. Safetysurf.com, for instance, is one of the most popular experts for parents and organisations to choose tools for monitoring Internet use (SafetySurf, 2002). Surveillance software may prove ineffective when utilised in large school populations. It also raises the issue of privacy invasion, and may cause a lack of trust between students and schools.

Yet regulating what students can or should view on the Internet in schools will be a principal concern for policy makers in the education system. Hopefully, filtering and surveillance software will develop in a way that can balance the boundaries between free expression, privacy, and material that might be harmful to minors.

\section{Strategies for e-learning implementation}

A final goal of this paper is to establish strategies for implementing elearning into school systems. These strategies represent fundamental and specific recommendations for educators, school administrators and policy makers.

\section{Inform educators about e-learning}

Before any campaign can be implemented, the potential benefactors need to be informed of the opportunities and challenges. Educators and administrators need to be aware of the benefits of e-learning in the classroom, as well as the specific technologies involved. Surveys and interviews can assess the current perceptions of using technology, and gauge any resistance. Then an e-learning campaign can be designed to inform teachers in an appropriate way.

After introducing technology to educators, showcasing innovative projects can have a great impact on introducing e-learning to schools. Innovative projects inspire teachers to be creative, and help to remove prejudices and resistance, by promoting teacher awareness of new methods for creating learning environments. 


\section{Create flexible training systems for teachers}

Once teachers are informed of the benefits and opportunities of e-learning, and once they are motivated to use e-learning in classroom design, they will need to be trained to use the technology and understand how best to incorporate e-learning into their teaching practice. Initial investments into developing training software is essential, but teaching teachers to train other teachers can reduce time and costs in getting people up to speed.

\section{Use e-learning to enhance, not substitute, traditional classroom teaching}

Hybrid forms of e-learning can serve to aid teachers in a variety of ways:

- Learning through active engagement by using interactive and entertaining multimedia.

- Learning through collaborative and cooperative activities.

- Learning through real world contexts.

- Learning through continuous feedback and monitoring progress.

E-learning can be integrated at a wide range of levels. Hybrid forms of elearning and traditional teaching can take the shape of very simple additions, like utilising email or a message board, or by using full scale virtual reality simulations. Some examples of successful e-learning additions include:

\section{Presentations and simulations}

Although presentations and simulations are not synchronous

interactions, they are effective as demonstrations that might grab the attention of students through the use of engaging production features. Scientific experiments and results, for instance, can be simulated for students and portray things students might not ordinarily see.

2. Interactive multimedia Interactive multimedia allows students to get closer to the learning material by actively engaging them to navigate through the content, play games or solve puzzles, engage in quizzes and practice drills and monitor their progress. Interactive multimedia can also help teachers to observe individual student progress easily, as the application can provide instant feedback.

3. Message boards, Instant Messenger, chat rooms and email

Reinforcing communication between teachers and peers, using tools such as message boards and chat rooms, cultivates a community of practice, where communities are built and sustained, knowledge is shared and cultured, and students learn to cooperate toward a common goal. 
4. Video conferencing and webcasts

Getting students closer to professional scientists, business people, and policy makers is an excellent method of empowering students and employing real world contexts to the subjects they study. Video conferencing allows a synchronous way to interact with people, while webcasts permit professionals to deliver a lecture or presentation from anywhere in the world. These technologieshelp to highlight how learning can be practical, and expose students to experts in diverse fields.

5. Virtual reality and artificial intelligence

Technologies continue to evolve, and virtual reality and artificial intelligence systems represent a future of learning where students become immersed in their learning environment, and learning tools become more aware of student needs. Imagine teaching Renaissance art by placing students in Florence, or a creating a virtual Socrates to ask and answer questions for students. As the software and machines become more intelligent and intuitive, and as the environments become more realistic and immersive, the future becomes very bright for creating learning environments.

\section{Leverage e-learning applications that can be used outside the classroom}

E-learning that is utilised outside the school halls encourages students to become life long learners. E-learning applications are anytime, anywhere, therefore assigning homework and projects that utilise the Internet after school are ways to expand learning. Creating activities using the Internet may provide new opportunities for parents to become more involved in their children's learning.

\section{Embrace standardised e-learning solutions to foster interoperability, ease of use and scalability}

Educators and administrators need to be aware of the best ways to invest in and implement technologies. By choosing vendors and software packages that are built with open standards, e-learning infrastructure remains flexible and scalable. As new tools hit the market, integrating these tools on top of older versions will not prove difficult or expensive, and keep schools that use e-learning on the cutting edge. Standards also allow more competition between vendors, so that more innovation occurs and schools are less likely to be locked into proprietary systems. 


\section{Lose the "E" in e-learning}

One day e-learning will become the norm as educators, administrators, policy makers, parents and students realise how e-learning can enhance the learning experience. It offers a chance to redefine how education is designed and reconnect the classroom, bringing teachers and students closer together using the technology that manifests in society.

\section{Conclusion}

This paper has identified key concepts of the new science of learning as advocated by the National Research Council, such as active learning, metacognition and transfer of learning, and demonstrated how e-learning applications embrace these concepts through active engagement, social learning, continuous feedback and real world applications. E-learning applications can be personalised to the learner's needs and still provide communication tools that foster collaborative, pro-social work. Since elearning offers an anytime-anywhere transfer of information, it cultivates learning both inside and outside the classroom.

This paper has also explored some of the costs and externalities that educators and school administrators might consider when making policy choices or designing e-learning applications for the classroom. These issues surround teacher training, content and application standardisation, cheating among students, and software filters and surveillance.

Finally, this paper has made recommendations for strategies in e-learning implementation. Informing and training educators is the first step in promoting classroom re-connection. Resistance may take shape in different forms, but it is important to envision e-learning as a way to enhance, not substitute traditional classroom teaching. Yet, with its technical advantages, e-learning also offers ways to continue teaching and learning outside of the classroom.

Further research into success stories of e-learning applications in public schools will encourage educators and policy makers to become more deeply involved with e-learning in classroom design and pedagogy.

\section{References}

Advocacy Project (2002). eRiders - Information and Communications Technology Support Providers. Washington DC: The Advocacy Project. [verified 23 Sep 2003] http: / / www.advocacynet.org/eRiders.html 
ALA (2002). ALA's Web Site on the Children's Internet Protection Act (CIPA). Washington DC: American Library Association. http:/ / www.ala.org/cipa/

Blackboard (2002). Washington DC: Blackboard, Inc. http: / / www.blackboard.com/

Bransford, J., Brown, A. and Cocking, R. (Eds) (2000). How People Learn: Brain, Mind, Experience, and School. Washington DC: National Research Council. http: / / www.nap.edu/html/ howpeople1/

Calvert, S. L. (1999). Children's Journeys Through the Information Age. New York: McGraw Hill.

Cassell, J. (2002). "We have these rules inside": The effect of exercising voice in a children's online forum. In S.L. Calvert, A.B. Jordan, and R.R. Cocking (Eds), Children in the Digital Age: Influences of Electronic Media on Development. Westport, CT: Praeger.

FCC (2002). Children's Internet Protection Act: Consumer Facts. http: / ftp.fcc.gov/cgb/ consumerfacts / cipa.html

Globe (2002). The Globe Program. Washington DC: The Globe Program. http: / / www.globe.gov/ fsl/html/aboutglobe.cgi?intro\&lang=en\&nav=1 [verified 23 Sep 2003]

Horton, W. K. (2000). Designing Web-Based Training: How to Teach Anyone, Anything, Anywhere, Anytime. New York: Wiley.

IEARN (2002). New York: International Education and Resource Network. [verified 23 Sep 2003] http:/ / www.iearn.org/ projects / index.html

IEEE (2002). IEEE Learning Technology Standards Committee. [verified 23 Sep 2003] http:/ / ltsc.ieee.org/

IFEA (2002). Children's Internet Protection Act (Pub. L.106-554). New York: Internet Free Expression Alliance. [verified 23 Sep 2003] http:/ / www.ifea.net/ cipa.html

IMS (2002). IMS Global Learning Consortium. http: / / www.imsproject.org/

Macromedia (2002). Authorware. San Francisco: Macromedia, Inc. http: / / www.macromedia.com/software/authorware/

McCabe, D.L. (2001). Student Cheating in American High Schools. http: / / www.academicintegrity.org/hs01.asp

NCES (2001). Internet Access in U.S. Public Schools and Classrooms 1994-2001. Washington D.C.: National Institute for Education Statistics. [verified $23 \mathrm{Sep}$ 2003] http:/ / nces.ed.gov/ pubs2002/internet/3.asp 
PEW (2002). The Digital Disconnect: The Widening Gap Between Internet-Savoy Students and Their Schools. Washington DC: Pew Internet and American Life

Project. http:/ / www.pewinternet.org/reports / pdfs / PIP_Schools_Internet_Report.pdf

Phillips, R. (1997). The Developer's Handbook of Interactive Multimedia. Kogan Page: London.

Roschelle, J.M., Pea, R.D., Hoadley, C. M. Gordin, Douglas N. \& Means, B.M. (2000). Changing How and What Children Learn in School with Computer-Based Technologies.

http: / / www.sri.com/policy/ctl/assets / images / RoschelleEtAlPackard2000.pdf

Rosenberg, M. J. (2001). E-Learning: Strategies for Delivering Knowledge in the Digital Age. New York: McGraw-Hill.

SafetySurf (2002). http: / / www.safetysurf.com/

Twigg, C. (2002). Quality, cost and access. In Pittinsky, M. (Ed), The Wired Tower. New York: Prentice Hall.

David Huffaker is a Master's Candidate in the in Communication, Culture, and Technology Program at Georgetown University. After finishing a Philosophy and Digital Media undergraduate degree, he worked for five years designing and developing Internet and multimedia applications. Dave is especially interested in developing e-learning applications that foster student learning and achievement.

David Huffaker

Communication, Culture and Technology

Georgetown University, USA

http: / / cct.georgetown.edu/

http: / / cdmc.georgetown.edu/team_members.cfm

Email: dah24@georgetown.edu 